\title{
Larvicidal activity of Maytenus guianensis (Celastraceae) against Aedes aegypti (Diptera: Culicidae)
}

\author{
Mirilene Mendes Martins ${ }^{[1]}$, Alyne Cunha Alves Dias ${ }^{[2]}$, Valdir Alves Facundo ${ }^{[3]}$, \\ Renato Abreu Lima ${ }^{[4]}$, Dionatas Ulises de Oliveira Meneguetti ${ }^{[5]}$ \\ and Alexandre de Almeida e Silva ${ }^{[1],[6]}$
}

\begin{abstract}
[1]. Universidade Federal de Rondônia, Laboratório de Bioecologia de Insetos, Departamento de Biologia, Porto Velho, RO, Brasil. [2]. Universidade Federal de Rondônia, Programa de Pós-Graduação em Biologia Experimental, Porto Velho, RO, Brasil.

[3]. Universidade Federal de Rondônia, Departamento de Química, Porto Velho, RO, Brasil.

[4]. Universidade Federal do Amazonas, Departamento de Ciências, Biologia e Química, Humaitá, AM, Brasil.

[5]. Universidade Federal do Acre, Colégio de Aplicação,

Programa de Pós-Graduação Stricto Sensu em Ciência, Inovação e Tecnologia para a Amazônia, Rio Branco, AC, Brasil.

[6]. Fundação Oswaldo Cruz Rondônia, Instituto Nacional de Epidemiologia da Amazônia Ocidental, Porto Velho, RO, Brasil.
\end{abstract}

\begin{abstract}
Introduction: Bioprospection of plant products is used to discover new insecticides. Methods: The larvicidal activity of ethanolic extract and triterpene (tingenone B) from the bark of Maytenus guianensis and their effect on pupation and emergence were evaluated against Aedes aegypti. Results: Crude extract $\mathrm{LC}_{50}$ was $11.3 \mathrm{ppm}$ and caused ejection of the larvae intestine; tingenone $\mathrm{B} \mathrm{LC}_{50}$ was 14.8 ppm. Pupation was reduced by $20 \%$ and $10 \%$, respectively; however, the emergence was not affected. Conclusions: The crude bark extract exhibited a higher larvicidal effect against the vector.
\end{abstract}

Keywords: Vector control. Insecticide. Larvicidal activity. Bioprospection. 22ß-hydroxytingenone. Dengue mosquito.

The Aedes aegypti (Diptera: Culicidae) mosquito transmits several arboviruses, such as yellow fever, dengue, chikungunya, and zika. Chemical control strategies for this mosquito include natural products derived from plants as potential insecticides ${ }^{1}$.

Recently, the insecticidal activity of plants against mosquitoes has been immensely explored, thereby revealing that some plants display remarkable larvicidal activity against different vector mosquitoes (Pavela et al. ${ }^{2}$ for a review) and act as potential sources of new insecticides. The Celastraceae family is represented by four genera; among these, Maytenus, the largest genus with 225 species, includes Maytenus guianensis, an endemic species from the Amazon, popularly known as chichuá, which presents several biological activities, such as leishmanicidal and antibacterial properties ${ }^{3,4}$.

\footnotetext{
Corresponding author: Dr. Alexandre de Almeida e Silva.

e-mail: alealsil@unir.br

(D) https://orcid.org/0000-0002-6500-0402

Received 7 December 2020

Accepted 17 March 2021
}

The present study evaluated the insecticidal effect of ethanolic extract of M. guianensis (Celastraceae) bark and of tingenone B, an isolated triterpene with proven biological activity ${ }^{3}$ against A. aegypti, due to their potential application in biotechnology.

Colonized $A$. aegypti were reared according to a previously described lab methodology ${ }^{5}$. Briefly, females of different generations were fed artificial feeders ${ }^{6}$ and researchers' blood. After the blood feed, females were placed in cages and were fed $10 \%$ sucrose soaked in cotton. Dark $50 \mathrm{ml}$ plastic cups were placed inside the cages, lined with filter paper to collect eggs for 3 days. The eggs were placed in $25 \times 5 \times 6 \mathrm{~cm}$ plastic trays with $1000 \mathrm{ml}$ of dechlorinated water, which were cleaned every 3 days. First larval instars (L1 and L2) were fed ground TetraMin Tropical Flakes fish food. From instars L3 and L4, larvae were separated for larvicidal tests. The experiments were carried out in the laboratory at a temperature of $27-28{ }^{\circ} \mathrm{C}$ and a $12-\mathrm{h}$ photoperiod. The research was approved by the Research Ethics Committee of the Fundação Oswaldo Cruz, protocol number 73001316.4.0000.5248.

M. guianensis bark was collected from the Adolpho Ducke Forest Reserve, located at $26 \mathrm{~km}$ on the Manaus Itacoatiara road 
(AM-010) (latitude $02^{\circ} 53$ 'S, longitude $59^{\circ} 58$ 'W) in Manaus, Amazonas state. The species was identified by Dr. José Eduardo da Silva from the Herbarium of the National Research Institute of the Amazon (Instituto Nacional de Pesquisas da Amazônia [INPA]), and exsiccate no. 188,485 was sent to the Laboratory of Natural Products Chemistry at the Federal University of Rondônia (Universidade Federal de Rondônia [UNIR]).

Dried and ground bark was placed in a Soxhlet extractor, and hexane, chloroform, ethyl acetate, methanol, and ethanol were used to produce crude extracts. The ethanolic extract presented the highest yield and was used in the present study. Tingenone B (22ß-hydroxytingenone) was obtained from the hexanic extract. We separated the hexanic extract by using silica gel column chromatography, and eluted it with n-hexane, followed by a mixture of n-hexane: $\mathrm{CHCl}_{3}$, which had greater polarity. Moreover, we determined the structures of all isolated compounds by analyzing their spectral data (IR, MS, ${ }^{1} \mathrm{H}$, and ${ }^{13} \mathrm{C}$, including COSY, HMQC, $\mathrm{HMBC}$, and NOESY spectra) and comparing them with the existing literature data ${ }^{3}$.

For larvicidal tests, the crude extract was solubilized in dimethyl sulfoxide PA (1\%) and tingenone B in ethanol PA (1\%). Five different concentrations of the crude extract $(30,22,18,16$, and 14 $\mathrm{ppm})$ and of the isolated substance $(30,25,20,15$, and $10 \mathrm{ppm})$ were used to calculate the lethal concentrations $\mathrm{LC}_{50}$ and $\mathrm{LC}_{90}$. Control groups for crude extract and tingenone $\mathrm{B}$ were dimethyl sulfoxide PA (1\%) and ethanol PA (1\%), respectively.

Furthermore, 25 L3/L4 instar larvae were used for each concentration during the bioassay. The larvae were transferred to $150 \mathrm{ml}$ plastic cups, with $100 \mathrm{ml}$ of tested solution each, and were monitored at 24-h intervals for up to $96 \mathrm{~h}$ of exposure to record the mortality ${ }^{7}$. During the follow-up period, the larvae were fed reptile food grains (Reptolife ${ }^{\circledR}$ ).
Later, $96 \mathrm{~h}$ after the larvicidal test, we cleaned the containers and followed the live larvae up to the pupa stage, to calculate the pupation rate by dividing the number of pupae by the number of surviving larvae. The pupae were transferred to disposable cups with $10 \mathrm{ml}$ of dechlorinated water and placed in screened cages until the adults emerged. We calculated the emergence rate by dividing the number of adults by the number of pupae.

Three replicates of the bioassays were performed with four repetitions, on different days with different generations. The temperature during the experiments was $25^{\circ} \mathrm{C}-28{ }^{\circ} \mathrm{C}$ with a $12-\mathrm{h}$ photoperiod and $70 \%-80 \%$ humidity.

We employed the probit method to analyze the data from the mortality assays (dosage $\times$ mortality) to obtain $\mathrm{LC}_{50}$ and $\mathrm{LC}_{90}$, using the Minitab 14 (MINITAB LLC.). The effects of different concentrations of bark extract and tingenone $\mathrm{B}$ on larval mortality were examined via one-way analysis of variance (ANOVA); the pupation and emergence rates were analyzed with the KruskalWallis test (nonparametric ANOVA), and data was compared using the Tukey's test with Prism 8 (GraphPad LLC).

The average larval mortality rate was significantly affected by the crude bark extract $(F=367.3 ; p<0.0001)$ and the isolated substance (tingenone $\mathrm{B} ; F=33.83 ; p<0.0001$ ) of $M$. guianensis, with a significant increase in larval mortality corresponding with increased concentration (Figure 1).

The lowest concentrations of the crude extract (14 ppm) and tingenone $\mathrm{B}(10 \mathrm{ppm})$ exhibited larval mortality rates of $66 \%$ and $3 \%$, respectively. In contrast, the highest concentration (30 ppm) of crude extract and tingenone $\mathrm{B}$ revealed mortality rates higher than $80 \%$.

Interestingly, the exposure of larvae to the crude extract led to a total ejection of the digestive tract by the larvae (Figure 2).

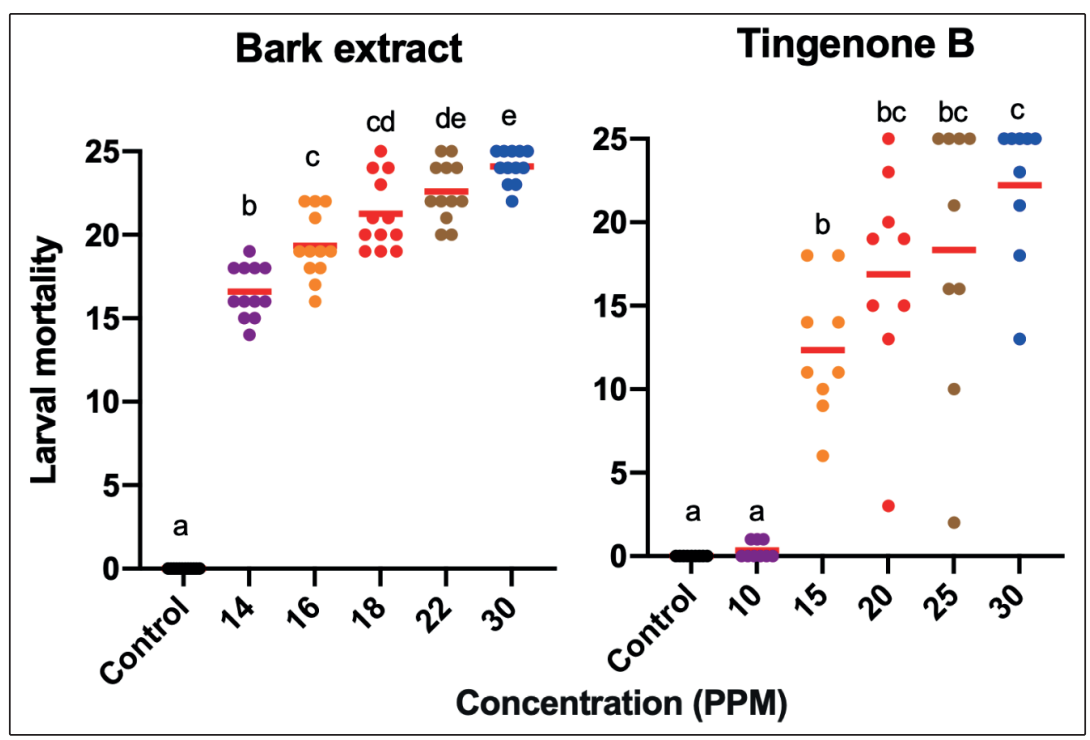

FIGURE 1: Mortality rates of Aedes aegypti larvae exposed to different concentrations of Maytenus guianensis crude bark extract and tingenone B after $48 \mathrm{~h}$. Different letters indicate significant differences between concentrations $(p<0.05)$. The red lines indicate the average concentration. 


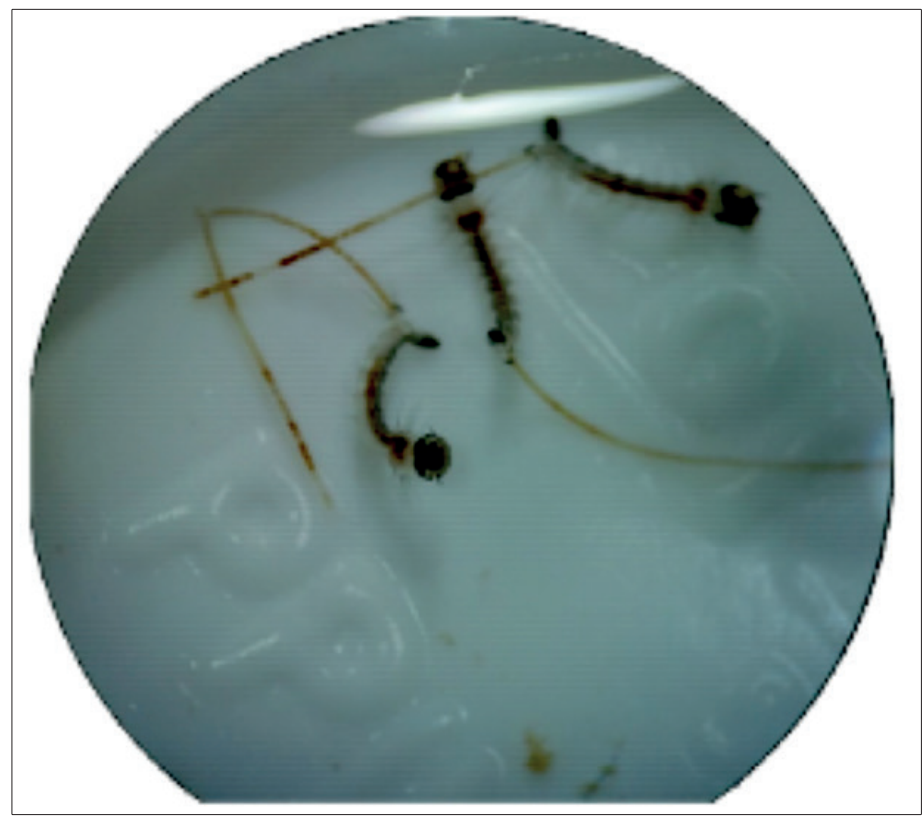

FIGURE 2: Aedes aegypti larvae with ejected intestine after contact with Maytenus guianensis crude bark extract. Photograph: Mirilene Martins, 2019.

Lethal concentrations $\left(\mathrm{LC}_{50}\right.$ and $\left.\mathrm{LC}_{90}\right)$ required to kill larvae were lower for the M. guianensis bark extract, that is, $11.3 \mathrm{ppm}$ (lower and upper $\mathrm{CI}=10.1-12.2 \mathrm{ppm}$ ) and $21.4 \mathrm{ppm}$ (lower and upper $\mathrm{CI}=20.2-23.1 \mathrm{ppm})$, respectively, compared to those of tingenone $\mathrm{B}$, that is, $14.8 \mathrm{ppm}$ (lower and upper $\mathrm{CI}=12.1-16.6 \mathrm{ppm}$ ) and 31.2 ppm (lower and upper CI $=29.4-33.8 \mathrm{ppm}$ ), respectively.

In general, larval exposure during the experimental period significantly reduced the pupation rate $(H=16.9 ; p=0.0002)$ by approximately $20 \%$ and $10 \%$ for crude extract and tingenone B, compared to the control; however, no significant effect was observed on adult emergence $(H=3.63 ; p=0.16)$ (Figure 3).
Although no evidence exists on the insecticidal effect of M. guianensis on A. aegypti, studies have reported that ethyl acetate extract from the stem of Maytenus oblongata at a concentration of $100 \mathrm{ppm}$ killed $95 \%$ and $83 \%$ of the strains of Paea (susceptible to pyrethroids) and Cayenne (resistant to pyrethroids) of this species, respectively ${ }^{8}$. In contrast, ethanolic extract of Maytenus rigida leaves at 500 ppm exhibited only $15 \%$ mortality rate on the mosquito larvae ${ }^{9}$. Nevertheless, in our experiment, the ethanolic extract of the M. guianensis bark efficiently killed $96 \%$ of the larvae larvae in concentrations that were 3 and 16 times lower compared to those used in the previous studies, respectively.

Furthermore, in tests carried out with crude ethanolic extracts from the bark of M. guianensis, Macari et al. ${ }^{10}$ reported an $\mathrm{LC}_{50}$ of 1230 ppm for larvae of the crustacean Artemia franciscana in $20 \mathrm{~h}$, which was approximately 100 times greater than that observed for larvae of $A$. aegypti; however, the bark extract samples with medium- and low-polarity solvents, for example, chloroform, had remarkably lower LCs (17 ppm), suggesting that compounds, such as tingenone B, with a higher insecticidal effect, may be found in extracts with lower polarity.

Additionally, the insecticidal effect also varies in different parts of a Maytenus plant, since the ethanolic extracts of Maytenus boaria seeds applied under mulberry leaves (Rubus ulmifolius) displayed an average insecticidal activity of about $80 \%$ against mulberry weevils (Aegorhinus superciliosus), but less than $40 \%$ when the bark extract of the same species was used ${ }^{11}$. Therefore, the chemical composition of different parts of the Maytenus plant may contribute to marked differences in its insecticidal effect, and these need to be further investigated.

To date, no studies have reported the insecticidal activity of tingenone B; however, Meneguetti et al. ${ }^{3}$ reported that this substance was the most active triterpene of $M$. guianensis and completely inhibited the growth of Leishmania amazonensis promastigotes at $100 \mathrm{ppm}$ concentration. Interestingly, the lepidopteran larvae Cydia pomonella, fed on a diet containing a similar molecule,

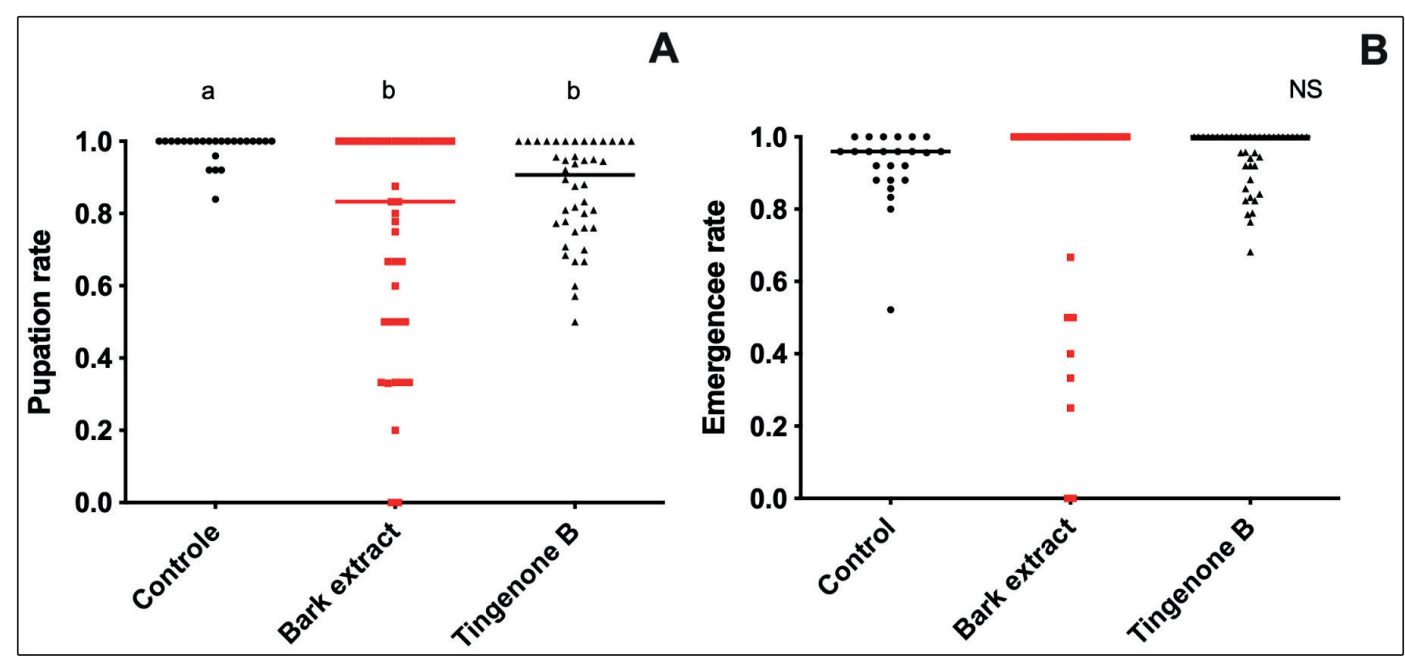

FIGURE 3: Pupation rate (A) and emergence rate (B) of Aedes aegypti from larvae exposed to Maytenus guianensis crude ethanolic bark extract and tingenone B. Different letters indicate significant differences between the groups $(p<0.05)$. NS $=$ Not significant $(p>0.05)$. Lines indicate the median. 
20- $\alpha$-hydroxytingenone, presented an $\mathrm{LC}_{50}$ of $13.0 \mathrm{mg} / \mathrm{mL}(13,000$ ppm) after 5 days of feeding ${ }^{12}$; whereas for $A$. aegypti, the $\mathrm{LC}_{50}$ was $15 \mathrm{ppm}$ after $48 \mathrm{~h}$ of contact, thereby suggesting that changes in the position of functional groups are related to the insecticidal potential of these triterpenes.

Besides its larvicidal effect, exposure to the bark ethanol extract and tingenone $\mathrm{B}$ also reduced the $A$. aegypti pupation rate, which might be related to the deterrent (antifeeding) effect that has already been reported for extracts from other Maytenus and insect species ${ }^{13}$.

In conclusion, the $M$. guianensis bark extract had lower $\mathrm{LC}_{50}$ and $\mathrm{LC}_{90}$ values for $A$. aegypti compared to tingenone $\mathrm{B}$, suggesting that other relevant insecticidal molecules, besides tingenone $\mathrm{B}$, are present in the crude extract and cause morphological changes as well as potentially synergistic effects leading to the death of A. aegypti larvae (Figure 2). Previous studies have reported other molecules in $M$. guianensis bark extracts, including friedelin, friedenol, 16 $\beta$-hydroxyfriedelin, 29-hydroxyfriedelin, tingenone, and $22 \beta$-hydroxypristimerin ${ }^{14}$; these should be tested alone or in combination in future experiments when available.

\section{ACKNOWLEDGMENTS}

We thank the laboratory team (LaBEIn) for all their support, especially Jayr Torres, Debora Aline, and Scientific Initiation colleagues Amanda Santos, Claudia Christian, and Raquel Vianna for their support with the experiments. We also thank Fundação de Amparo ao Desenvolvimento das Ações Científicas e Tecnológicas e a Pesquisa de Rondônia (FAPERO) and Instituto Nacional de Epidemiologia da Amazônia Ocidental (INCT-EpiAmo) for providing the scholarships that supported the experiments.

\section{FINANCIAL SUPPORT}

This study was supported by Fundação de Amparo ao Desenvolvimento das Ações Científicas e Tecnológicas e a Pesquisa de Rondônia (FAPERO) and Instituto Nacional de Epidemiologia da Amazônia Ocidental (INCT-EpiAmo).

\section{ORCID}

Mirilene Mendes Martins: 0000-0001-9076-4538

Alyne Cunha Alves Dias: 0000-0001-6391-8263

Valdir Alves Facundo: 0000-0002-0854-9490

Renato Abreu Lima: 0000-0003-0006-7654

Dionatas Ulises de Oliveira Meneguetti: 0000-0002-1417-7275

Alexandre de Almeida e Silva: 0000-0002-6500-0402

\section{AUTHORS' CONTRIBUTION}

VAF, DUOM and RAL: prepared the extracts and isolated Tingenone B (Acquisition of data) and revised and edited the final version of the manuscript; MMM: performed the larvicidal experiments (Acquisition of data), tabulated the data and wrote the original draft; ACAD: supervised the larvicidal experiments (methodology supporting), wrote the original draft and AAS: analyzed the data (Methodology lead), wrote the original draft and revised and edited the final version of the manuscript, and lead the project administration.

\section{CONFLICT OF INTEREST}

The authors declare no conflict of interest.

\section{REFERENCES}

1. Zara AL, Santos SM, Fernandes-Oliveira ES, Carvalho RG, Coelho GE. Aedes aegypti control strategies: a review. Epidemiol Serv Saúde. 2016;25(2):391-404.

2. Pavela R, Maggi F, Iannarelli R, Benelli G. Plant extracts for developing mosquito larvicides: from laboratory to field, with insights on the modes of action. Acta Trop. 2019;193:236-71.

3. Meneguetti DUO, Lima RA, Hurtado FB, Passarini GM, Macedo SRA, Barros NB, et al. Screening of the in vitro antileishmanial activities of compounds and secondary metabolites isolated from Maytenus guianensis Klotzsch ex Reissek (Celastraceae) chichuá Amazon. Rev Soc Bras Med Trop. 2016;49(5):579-85.

4. Silva TM, Carvalho CM, Lima RA, Facundo VA, Cunha RM, Meneguetti DUO. Antibacterial activity of fractions and isolates of Maytenus guianensis Klotzsch ex Reissek (Celastraceae) Chichuá Amazon. Rev Soc Bras Med Trop. 2018;51(4):533-36.

5. Barbosa DD, Rodrigues MMS, Silva AAE. Evaluation of attractive toxic baits (ATSB) against Aedes aegypti (Diptera: Culicidae) in laboratory. Trop Biomed. 2019;36(2):578-86.

6. Siria DJ, Batista EPA, Opiyo MA, Melo EF, Sumaye RD, Ngowo HS, et al. Evaluation of a simple polytetrafluoroethylene (PTFE)-based membrane for blood-feeding of malaria and dengue fever vectors in the laboratory. Parasite Vector. 2018;11(1):236.

7. World Health Organization (WHO). Guidelines for laboratory and field testing of mosquito larvicides. Geneva: WHO; 2005. 41 p.

8. Touré S, Nirma C, Falkowski M, Dusfour I, Boulogne I, Jahn-Oyac A, et al. Aedes aegypti larvicidal sesquiterpene alkaloids from Maytenus oblongata. J Nat Prod. 2017;80(2):384-90.

9. Mendonça FAC, Silva KFS, Santos KK, Ribeiro KAL Jr, Sant'Ana AEG. Activities of some Brazilian plants against larvae of the Aedes aegypti mosquito. Fitoterapia. 2005;76(7-8):629-36.

10. Macari PAT, Portela CN, Pohlit AM. Antioxidant, cytotoxic and UVBabsorbing activity of Maytenus guianensis Klotzch. (Celastraceae) bark extracts. Acta Amaz. 2006;36(4):513-8.

11. Zavala HA, Hormazabal UE, Montenegro GR, Rosalez MV, Quiroz AC, Paz CR, et al. Effects of extracts from Maytenus on Aegorhinus superciliosus (Coleoptera: Curculionidae) and Hippodamia convergens (Coleoptera: Coccinellidae). Rev Colomb Entomol. 2017;43(2):233-44.

12. Avilla J, Teixido A, Velazquez C, Alvarenga N, Ferro E, Canela R. Insecticidal activity of Maytenus species (Celastraceae) nortriterpene quinone methides against codling moth, Cydia pomonella (L.) (Lepidoptera: Tortricidae). J Agric Food Chem. 2000;48(1):88-92.

13. Shadia E, El-Aziz A, El-Din AAE. Insecticidal activity of some wild plant extracts against cotton leafworm, Spodoptera littoralis (Boisd.) (Lepidoptera: Noctuidae). Pak J Biol Sci. 2007;10(13):2192-7.

14. Facundo VA, Meneguetti DUO, Militão JSLT, Lima RA, Hurtado FB, Casseb AA, et al. Chemical constituents from Maytenus guianensis Klotzsch ex Reissek (Celastraceae) Amazon rain forest. Biochem Syst Ecol. 2015;58:270-73. 